International Journal of Management Science and

Business Administration

Volume 2, Issue 5, April 2016,Pages 7-12

DOI: 10.18775/ijmsba.1849-5664-5419.2014.25.1001

URL: http://dx.doi.org/10.18775/ijmsba.1849-5664-5419.2014.25.1001

\title{
A Scenario Based Stochastic Time-Cost-Quality Trade-Off Model for Project Scheduling Problem
}

\author{
Hêriş Golpîra \\ Department of Industrial Engineering, Sanandaj Branch, Islamic Azad University, Sanandaj, Iran
}

\begin{abstract}
This paper formulates a new time-cost trade-off problem under some uncertainties for a multi-phase project. To do this, a new approach is proposed based on goal programming in compliance with scenario-based stochastic optimization formulation. To the best of our knowledge, this problem has not been extensively treated in the literature. Computational results show the applicability and usefulness of the proposed method.
\end{abstract}

Keywords: Time-cost-quality trade-off, stochastic optimization, goal programming.

\section{Introduction}

There are three project essential goals which are time, cost and quality, those are interdependent each other. In other words, a project desired result is achieving a reasonable duration; low cost and high quality. This paper formulates a balanced model of time-cost-quality optimization under resource constraints in a stochastic environment.

In a project scheduling, it is general to shorten duration of some activities through consuming extra budget to shorten the project total completion time. This approach, may be taken under either some pre-defined budget or a threshold of project completion time, is traditionally known as time-cost trade-off problem (TCTP). It is clear that this problem leads to a balance between the project completion time and its' total cost. Salmasnia et al. (2012) introduced that some TCTP studies can be classified to:

- stochastic or deterministic environment that forces the network to be CPM (Hazır et al., 2010a), PERT (Abbasi and Mukattash, 2001; Foldes and Soumis, 1993; Mokhtari et al., 2010) or GERT (Arisawa and Elmaghraby, 1972);

- cost function behavior which may be discrete (Bregman, 2009), linear continuous (Mitchell and Klastorin, 2007), nonlinear convex (Peyghami et al., 2013) and linear-piecewise (Vrat and Kriengkrairut, 1986);

- controllable variable in cost function may be in the modes of activities with allocated budget (Abbasi and Mukattash, 2001) or resources (Sunde and Lichtenberg, 1995);

- response variable in cost function may be activity costs (Sunde and Lichtenberg, 1995) or its' durations (Godinho and Costa, 2007);

- type of distribution function of cost and duration may be Beta (Abbasi and Mukattash, 2001), Normal (Golenko-Ginzburg and Gonik, 1998) or Exponential and Erlang (Azaron and Tavakkoli-Moghaddam, 2006);

- objective function can be maximizing project completion probability in a predefined deadline with limited budget (Abbasi and Mukattash, 2001), minimizing direct cost to obtain a pre-defined threshold of mean completion time (Foldes and Soumis, 1993), minimizing direct cost to reach a predefined threshold of project completion probability in a deadline (Mokhtari et al., 2010), minimizing the total cost, including direct and indirect approaches (Gutjahr et al., 2000), minimizing mean of project completion time and minimizing variance of completion time and cost (Azaron and Tavakkoli-Moghaddam, 2006) and minimizing mean of project completion time and minimizing mean of total project cost (Godinho and Costa, 2007); 
- the solution approaches containing exact approaches (Arisawa and Elmaghraby, 1972; Azaron and TavakkoliMoghaddam, 2006; Gutjahr et al., 2000), Heuristic approaches (Bregman, 2009; Foldes and Soumis, 1993) and meta-heuristic approaches (Aghaie and Mokhtari, 2009).

The above researches consider only two dimensions of the projects, i.e. time and cost, but the other critical project dimension, i.e. quality, is completely missed. Babu and Suresh (1996) introduced that the quality of the project may be affected by project crashing and developed a linear programming model to study the time-cost-quality trade-off (TCQTP). Khang and Myint (1999) applied the same method on an actual cement factory construction project in Thailand. El-Rayes and Kandil (2005) designed a model as a multi-objective genetic algorithm to transform the traditional TCTP to an advanced three-dimensional TCQTP. Iranmanesh et al. (2008) proposed a discrete multi-mode model of TCQTP to deal with the problem. Pour et al. (2012) proposed fuzzy logic theory to consider affecting uncertainty in project quality for discrete TCQTP. Zheng (2014) presented a fuzzy time-cost-quality trade-off problem for construction project and establishes a decision making model with multiple modes under resource-constrained environment. Golpîra and Hejazi (2014) proposed a scenario based stochastic TCQTP over a multi-objective approach under this assumption that the probability of each scenario is available.

This paper formulates a TCQTP based on scenario based stochastic optimization for multi-phase project scheduling problem (SP). SP applies probabilistic models to deal with uncertain data in terms of probability distributions. When accurate distributional information is available, stochastic programming has the advantage of incorporating this available distributional data; however, stochastic programming models are usually computationally more demanding (Hazir et al., 2010b). To do this, we use a goal programming approach in order to deal with the budget constraint. Our research and Golpîra and Hejazi (2014) address a TCQTP through the same methodology; however the approaches and the contributions of these papers are quite different. Golpîra and Hejazi (2014) introduce a stochastic approach and their model is not addresses the uncertainty of the entire project costs unless the costs related directly to the duration of activities. But in this research, we use the approach that is introduced by Mulvey et al. (1995) in new point of view that uses a goal programming idea to obtain stochastic modeling. To the best our knowledge, this paper is the first research to introduce this approach. The remainder of this paper is organized as follows: Section 2 defines the proposed TCQTP. Section 3 presents an illustrative example to investigate the effectiveness of the developed method. Finally, the concluding remarks are reported in Section 4.

\section{Problem Statement}

A scenario based stochastic multi-objective modeling for TCTP is as follows:

$$
\begin{array}{ll}
\text { Minimiz } \mathrm{z}= & \left(\sum_{s=1}^{S} \sum_{i=1}^{I} p_{s}\left(d_{s i}^{+}+d_{s i}^{-}\right)\right)+\left(\left(\sum_{p=1}^{P} p_{s} \sum_{s=1}^{S} a_{s p} x_{s p}\right)+\delta\left(\sum_{s=1}^{S} p_{s}\left(\Omega_{s}^{+}+\Omega_{s}^{-}\right)\right)\right) \\
\text {s.t }: \quad & \sum_{p=1}^{P} x_{s p}-d_{s i}^{+}+d_{s i}^{-}=T_{s} \quad, s=1, \ldots, S, i=1, \ldots, I \\
& \sum_{p=1}^{P} c_{s p} x_{s p}-d_{s i}^{+}+d_{s i}^{-}=T C_{s} \quad, s=1, \ldots, S, i=1, \ldots, I \\
& \sum_{p=1}^{P} l_{s p} x_{s p}-d_{s i}^{+}+d_{s i}^{-}=Q_{s}, s=1, \ldots, S, i=1, \ldots, I \\
& \sum_{p=1}^{P} a_{s p} x_{s p}-p_{s} \sum_{p=1}^{P} \sum_{s=1}^{S} a_{s p} x_{s p}=\Omega_{s}^{+}-\Omega_{s}^{-} \quad, \mathrm{s}=1, \ldots, S \\
& x_{s p} \geq 1, \quad s=1, \ldots, S, i=1, \ldots, I \\
& d_{s i}^{+}, d_{s i}^{-} \geq 0, \quad s=1, \ldots, S, i=1, \ldots, I \\
& \Omega_{s}^{+}, \Omega_{s}^{-} \geq 0, \quad s=1, \ldots, S .
\end{array}
$$

The index $s$ is the scenario number, $i$ is the constraint number and $p$ is the project phase number. $p_{s}$ is the probability of the scenarios and $d_{s i}^{+}, d_{s i}^{-}$are respectively the under-achievement and over-achievement of the $i^{\text {th }}$ goal of the scenario 
set. $x_{s p}$ is the duration of phase $p$ over scenario $s$.

Constraint (1) represents the total cost of the project that is contains the expected amount of the deviational variables in the first term, and the human resource cost variability and model infeasibility penalty in the last term. Constraint (2) denotes the total estimated time of the project. $T_{s}$ in this constraint, is the total time of the project over scenario $s$. Constraint (3) reveals the relation between total cost of the project and the duration of the phases of the project. The parameter $T C_{s}$ in this constraint is the total cost of the project over scenario $s$ except the costs of human resources. Constraint (4) explains the linkage between phase's duration and the quality that must be achieved. $Q_{s}$ in this constraint is total quality achieved over scenario $s$. $\delta$ is the penalty that is assigned to control the deviation which may be accrued in constraint (5). This constraint contains the cost of human resources and the parameter $a_{s p}$ is the per-unit human resource for phase $p$ over scenario $s$ of the project. Constraints (6)-(8) reveal the positivity of the variables. The two additional variables, $\Omega_{s}^{+}, \Omega_{s}^{-}$are interpreted as the amount by which the expected value of the human resource costs is less or more than the exact one according to the scenarios, respectively.

\section{Simulation and Results}

To illustrate the usefulness and practicability of the proposed approach, an empirical case is studied. A real project containing three phases- planning, scheduling and controlling- is given as a case. The data for this study are collected in winter 2013 in Kurdistan that is previously addressed by Golpîra and Hejazi (2014). The data of the problem are illustrated in Table 1 and Table 2.

Table 1: Problem data of each scenario over each scenario Golpîra and Hejazi (2014)

\begin{tabular}{|c|c|c|c|c|c|c|c|}
\hline \multirow[t]{2}{*}{ Scenario } & \multirow[t]{2}{*}{$\begin{array}{c}\text { Probability of } \\
\text { Scenarios }\end{array}$} & \multirow{2}{*}{$\begin{array}{c}\text { Phases } \\
1\end{array}$} & \multicolumn{3}{|c|}{$\begin{array}{l}\text { Human and material } \\
\text { resource monthly cost }\end{array}$} & \multirow{2}{*}{$\begin{array}{l}\text { Other monthly } \\
\text { costs } \\
20\end{array}$} & \multirow{2}{*}{$\begin{array}{c}\begin{array}{c}\text { Monthly cost of } \\
\text { quality }\end{array} \\
30\end{array}$} \\
\hline & & & 29 & 26 & 27 & & \\
\hline \multirow{3}{*}{1} & \multirow{3}{*}{0.40} & 2 & 20 & 27 & 23 & 26 & 5 \\
\hline & & 3 & 15 & 27 & 15 & 30 & 20 \\
\hline & & 1 & 19 & 10 & 13 & 20 & 24 \\
\hline \multirow{3}{*}{2} & \multirow{3}{*}{0.35} & 2 & 17 & 21 & 19 & 18 & 4 \\
\hline & & 3 & 10 & 21 & 21 & 25 & 16 \\
\hline & & 1 & 15 & 13 & 22 & 18 & 22.5 \\
\hline \multirow{2}{*}{3} & \multirow{2}{*}{0.25} & 2 & 21 & 10 & 19 & 20 & 3.75 \\
\hline & & 3 & 17 & 16 & 14 & 40 & 15 \\
\hline
\end{tabular}

Table 2: Problem data of the total projectGolpîra and Hejazi (2014)

\begin{tabular}{cccc}
\hline Scenario & $\begin{array}{c}\text { Total cost of the } \\
\text { project }\end{array}$ & Timetable of the project & Total cost of quality of the project \\
\hline 1 & 1000 & 36 & 3.5 \\
2 & 800 & 30 & 3 \\
3 & 750 & 24 & 4 \\
\hline
\end{tabular}

The problem is a linear stochastic goal programming which is simply solvable by Lingo software. The results are shown in Table 3 . In this table symbol $k$ is assigned to enumerate the number simulations. 
Hêriş Golpîra

Table 3: Solution data about the empirical exam

\begin{tabular}{|c|c|c|c|c|c|c|}
\hline & & $\delta=0$ & & & $\delta=1$ & \\
\hline $\mathrm{k}^{\mathrm{th}}$ simulation & 1 & 2 & 3 & 1 & 2 & 3 \\
\hline$d_{11}^{+}$ & 0 & 0 & 0 & 0 & 0 & 0 \\
\hline$d_{11}^{-}$ & 2.2 & 2.2 & 2.2 & 14.54 & 20.38 & 2.2 \\
\hline$d_{12}^{+}$ & 0 & 0 & 0 & 0 & 0 & 0 \\
\hline$d_{12}^{-}$ & 0 & 0 & 0 & 370.4 & 545.66 & 0 \\
\hline$d_{13}^{+}$ & 0 & 0 & 0 & 0 & 0 & 0 \\
\hline$d_{13}^{-}$ & 1.68 & 1.68 & 1.68 & 2.29 & 2.58 & 1.68 \\
\hline$d_{21}^{+}$ & 2.48 & 9.85 & 9.85 & 2.48 & 9.85 & 9.46 \\
\hline$d_{21}^{-}$ & 0 & 0 & 0 & 0 & 0 & 0 \\
\hline$d_{22}^{+}$ & 0 & 0 & 0 & 0 & 0 & 0 \\
\hline$d_{22}^{-}$ & 0 & 0 & 0 & 0 & 0 & 7.76 \\
\hline$d_{23}^{+}$ & 0 & 0 & 0 & 0 & 0 & 0 \\
\hline$d_{23}^{-}$ & 0.88 & 1.17 & 1.17 & 0.88 & 1.17 & 1.19 \\
\hline$d_{31}^{+}$ & 0 & 0 & 0 & 0 & 6.48 & 4.97 \\
\hline$d_{31}^{-}$ & 4.2 & 4.2 & 4.2 & 4.03 & 0 & 0 \\
\hline$d_{32}^{+}$ & 0 & 0 & 0 & 0 & 0 & 0 \\
\hline$d_{32}^{-}$ & 0 & 0 & 0 & 0 & 0 & 0 \\
\hline$d_{33}^{+}$ & 0 & 0 & 0 & 0 & 0 & 0 \\
\hline$d_{33}^{-}$ & 2.63 & 2.63 & 2.63 & 2.62 & 2.37 & 0 \\
\hline$x_{11}$ & 1 & 1 & 1 & 1 & 1 & 1 \\
\hline$x_{12}$ & 1 & 1 & 1 & 1 & 1 & 1 \\
\hline$x_{13}$ & 31.8 & 31.8 & 31.8 & 19.45 & 13.61 & 31.8 \\
\hline$x_{21}$ & 1 & 37.85 & 37.85 & 1 & 37.85 & 37.46 \\
\hline$x_{22}$ & 1 & 1 & 1 & 1 & 1 & 1 \\
\hline$x_{23}$ & 30.48 & 1 & 1 & 30.48 & 1 & 1 \\
\hline$x_{31}$ & 1 & 1 & 1 & 1.29 & 20.43 & 7.62 \\
\hline$x_{32}$ & 1 & 1 & 1 & 1 & 1 & 12.06 \\
\hline$x_{33}$ & 17.8 & 17.8 & 17.8 & 17.66 & 9.05 & 9.28 \\
\hline$Q_{1}^{+}$ & 111.67 & 322.83 & 57.43 & 0 & 0 & 0 \\
\hline$Q_{1}^{-}$ & 0 & 0 & 0 & 0 & 0 & 0 \\
\hline$Q_{2}^{+}$ & 0 & 0 & 62.48 & 0 & 0 & 0 \\
\hline$Q_{2}^{-}$ & 73.53 & 168.26 & 0 & 0 & 0 & 0 \\
\hline$Q_{3}^{+}$ & 0 & 0 & 0 & 0 & 0 & 0 \\
\hline$Q_{3}^{-}$ & 75.73 & 280.96 & 179.36 & 0 & 0 & 0 \\
\hline Objective & 418.7664 & 595.8841 & 476.6866 & 498.5399 & 654.0337 & 536.244 \\
\hline
\end{tabular}


As one can see, the penalty coefficient $\delta$ which is assigned to control the human recourse cost variability is designed to be 0 or 1 . If the $\delta$ is 0 , the value of the variables $Q_{1}, Q_{2}, Q_{3}$ allowed to be nonzero as the human and material resource variability. But if the $\delta$ is 1 , the value of the variables $Q_{1}, Q_{2}, Q_{3}$ are zero. In other words, it forces the variability of the human and material resource costs to be zero. On the other hand, if the manager wants to have a less duration, he/she can chose the scenario 1 that forces the project quality to be less than what expected, but makes the total costs to have no change in $\delta=0$, and the human and material resource cost is forced to be more than its expected value. but it changes the total costs to be more than what expected, if the value of the $\delta$ is fixed on 1 . So, the manager enforced to have more human and material resource costs to reach the better level of quality and project completion time. In scenario 2, if the value of the $\delta$ is 1 , the manager encountered with extended project time and more cost of quality with no change in the human and resource cots and total costs. So, if the manager wants to have a fixed value of costs, he/she may encounter with some loss in quality and have extended project time. In scenario 3 , all of the parameters are not worst in comparison with their expected values. In other words, if the manager selects the scenario 3 , the trade-off is not needed and the project may be finished exactly.

\section{Conclusion}

In this paper, we consider the time-cost-quality trade-off problem in the field of project management under stochastic manner to handle the uncertainty of the real world project environment. The scenario approach is employed to deal with the problem. The results illustrate that the model exactly helps the decision maker to have some alternatives and in this decision making helps him/her to make better optimal trade-offs among all the critical factors of the project. In addition to handling uncertainty, the variety of scenarios that can be considered, numerous constraints that may be indicated in the model and its simplicity and solvability are making the model more flexible and practical in real worlds.

\section{References}

- Abbasi, G.Y., Mukattash, A.M., 2001. Crashing PERT networks using mathematical programming. International Journal of Project Management 19, 181-188, $\underline{\text { CrossRef }}$

- Aghaie, A., Mokhtari, H., 2009. Ant colony optimization algorithm for stochastic project crashing problem in PERT networks using MC simulation. The International Journal of Advanced Manufacturing Technology 45, 1051-1067, CrossRef

- $\quad$ Arisawa, S., Elmaghraby, S.E., 1972. Optimal time-cost trade-offs in GERT networks. Management Science 18, 589-599, CrossRef

- Azaron, A., Tavakkoli-Moghaddam, R., 2006.A multi-objective resource allocation problem in dynamic PERT networks. Applied Mathematics and Computation 181, 163-174, $\underline{\text { CrossRef }}$

- Babu, A., Suresh, N., 1996.Project management with time, cost, and quality considerations. European Journal of Operational Research 88, 320-327, CrossRef

- Bregman, R.L., 2009.A heuristic procedure for solving the dynamic probabilistic project expediting problem. European Journal of Operational Research 192, 125-137, CrossRef

- El-Rayes, K., Kandil, A., 2005.Time-cost-quality trade-off analysis for highway construction. Journal of construction Engineering and Management 131, 477-486, $\underline{\text { CrossRef }}$

- Foldes, S., Soumis, F., 1993. PERT and crashing revisited: Mathematical generalizations. European Journal of Operational Research 64, 286-294, CrossRef

- Godinho, P.C., Costa, J.P., 2007. A stochastic multimode model for time-cost tradeoffs under management flexibility. OR Spectrum 29, 311-334, CrossRef

- Golenko-Ginzburg, D., Gonik, A., 1998.A heuristic for network project scheduling with random activity durations depending on the resource allocation. International Journal of Production Economics 55, 149-162, CrossRef

- Golpîra, H., Hejazi, S., 2014. A Scenario Based Stochastic Multi-Objective Modeling for Time-Cost-Quality Trade-Off Problem, International Scientific Conference on Project Management in the Baltic Countries Riga, University of Latvia. 
- Gutjahr, W.J., Strauss, C., Wagner, E., 2000. A stochastic branch-and-bound approach to activity crashing in project management. INFORMS Journal on Computing 12, 125-135, CrossRef

- Hazır, Ö.,Haouari, M., Erel, E., 2010a. Discrete time/cost trade-off problem: A decomposition-based solution algorithm for the budget version. Computers \&Operations Research 37, 649-655, CrossRef

- Hazır, Ö.,Haouari, M., Erel, E., 2010b. Robust scheduling and robustness measures for the discrete time/cost trade-off problem. European Journal of Operational Research 207, 633-643, CrossRef

- Iranmanesh, H., Skandari, M., Allahverdiloo, M., 2008. Finding Pareto optimal front for the multi-mode time, cost quality trade-off in project scheduling, Proceedings of World Academy of Science, Engineering and Technology. Citeseer, 1307-6884.

- Khang, D.B., Myint, Y.M., 1999. Time, cost and quality trade-off in project management: a case study. International Journal of Project Management 17, 249-256, CrossRef

- Mitchell, G., Klastorin, T., 2007. An effective methodology for the stochastic project compression problem. IIE Transactions 39, 957-969, $\underline{\text { CrossRef }}$

- Mokhtari, H., Aghaie, A., Rahimi, J., Mozdgir, A., 2010. Project time-cost trade-off scheduling: a hybrid optimization approach. The International Journal of Advanced Manufacturing Technology 50, 811-822, CrossRef

- Mulvey, J.M., Vanderbei, R.J., Zenios, S.A., 1995. Robust optimization of large-scale systems. Operations research 43, 264-281, CrossRef

- Peyghami, M.R., Aghaie, A., Mokhtari, H., 2013. A New Mathematical Approach based on Conic Quadratic Programming for the Stochastic Time-Cost Tradeoff Problem in Project Management. International Journal of Engineering Science (2008-4870) 24.

- Pour, N.S., Modarres, M., Tavakkoli-Moghaddam, R., 2012. Time-Cost-Quality Trade-off in Project Scheduling with Linguistic Variables. World Applied Sciences Journal 18, 404-413.

- Salmasnia, A., Mokhtari, H., Abadi, I.N.K., 2012. A robust scheduling of projects with time, cost, and quality considerations. The International Journal of Advanced Manufacturing Technology 60, 631-642, CrossRef

- Sunde, L., Lichtenberg, S., 1995. Net-present-value cost/time tradeoff. International Journal of Project Management 13, 45-49, $\underline{\text { CrossRef }}$

- Vrat, P., Kriengkrairut, C., 1986. A goal programming model for project crashing with piecewise linear timecost trade-off. Engineering costs and production economics 10, 161-172, CrossRef, CrossRef

- Zheng, H., 2014. The Fuzzy Time-Cost-Quality-Environment Trade-off Analysis of Resource-Constrained Multi-mode Construction Systems for Large-Scale Hydroelectric Projects, Proceedings of the Seventh International Conference on Management Science and Engineering Management. Springer, 425-438, $\underline{\text { CrossRef, }} \underline{\text { CrossRef }}$ 